\title{
(6) OPEN ACCESS \\ Beyond clinical engagement: a pragmatic model for quality improvement interventions, aligning clinical and managerial priorities
}

\author{
Samuel Pannick, ${ }^{1}$ Nick Sevdalis, ${ }^{2}$ Thanos Athanasiou ${ }^{3}$
}

${ }^{1}$ NIHR Imperial Patient Safety Translational Research Centre, Imperial College London, London, UK

${ }^{2}$ Centre for Implementation Science, King's College London, London, UK

${ }^{3}$ Department of Surgery \& Cancer, Imperial College London, London, UK

\section{Correspondence to}

Dr Samuel Pannick, NIHR Imperial Patient Safety Translational Research Centre, Imperial College London, Room 503, Medical School Building, Norfolk Place, London W2 1PG, UK; s.pannick@imperial.ac.uk

Received 1 June 2015 Revised 8 October 2015 Accepted 13 October 2015 Published Online First 8 December 2015

\section{CrossMark}

To cite: Pannick $S$,

Sevdalis N, Athanasiou T. BMJ Qual Saf 2016;25:716-725.

\begin{abstract}
Despite taking advantage of established learning from other industries, quality improvement initiatives in healthcare may struggle to outperform secular trends. The reasons for this are rarely explored in detail, and are often attributed merely to difficulties in engaging clinicians in quality improvement work. In a narrative review of the literature, we argue that this focus on clinicians, at the relative expense of managerial staff, has proven counterproductive. Clinical engagement is not a universal challenge; moreover, there is evidence that managersparticularly middle managers - also have a role to play in quality improvement. Yet managerial participation in quality improvement interventions is often assumed, rather than proven. We identify specific factors that influence the coordination of front-line staff and managers in quality improvement, and integrate these factors into a novel model: the model of alignment. We use this model to explore the implementation of an interdisciplinary intervention in a recent trial, describing different participation incentives and barriers for different staff groups. The extent to which clinical and managerial interests align may be an important determinant of the ultimate success of quality improvement interventions.
\end{abstract}

\section{INTRODUCTION}

Over the last decade there have been considerable efforts to evaluate and improve the quality of healthcare delivery. Three to six per cent of inpatient deaths may be preventable, $^{1-4}$ and early attempts to foster better care invoked crew resource management in aviation, ${ }^{5}$ industrial quality assurance techniques ${ }^{6}$ and transparent outcome reporting. ${ }^{7}$ However, the pace of improvement remains sluggish, ${ }^{8}$ despite an awareness of how infrequently patients receive the best therapy already available. $^{9} 10$

Quality improvement (QI) interventions have enormous potential to improve healthcare delivery, but wellpublicised research successes have proved difficult to replicate outside the trial setting. ${ }^{11-17}$ Discrete QI interventions also struggle to outperform the secular trend towards system-wide improvement. ${ }^{17} 18$ The challenges of reproducing QI successes on a wider scale remain poorly understood, but two key factors are often cited: the engagement of clinical staff in the broader initiative, and the context in which it takes place. Neither clinical engagement ${ }^{19}$ nor context ${ }^{20}$ is well defined, yet the two have become de facto explanations for QI failure. Moreover, the numerous attempts to explain how context affects $\mathrm{QI}^{21-25}$ risk overwhelming researchers and clinicians, ${ }^{21}$ with limited 'how-to' support for those implementing change. ${ }^{20}$ Here, we discuss whether the focus on clinical staff is misplaced, and propose a novel, pragmatic model for the development and selection of effective, durable QI interventions.

In a narrative synthesis guided by insights from a recent trial (see box 1), we first explore the varying definitions of clinical engagement. We go on to discuss the specific challenges of clinical engagement in QI, and strategies shown to circumvent them. Next, we explore the role of managerial staff, whose importance in QI implementation has been underestimated. Bringing these concepts together, we outline a 'model for alignment', highlighting key factors of practical importance for successful QI. The model is then 
Box 1 Autoethnographic observations from the Hospital Event Analysis Describing Significant Unanticipated Problems (HEADS-UP) study ${ }^{8 \Xi}$

- The HEADS-UP study evaluated an interdisciplinary team intervention tailored for general medical wards: a structured, daily safety and quality briefing. ${ }^{83} 92$

- HEADS-UP briefings were designed to embed proactive organisational risk surveillance into routine ward care. Through structured discussion, clinical staff would identify risks to the delivery of high quality care on a daily basis, addressing them promptly through facilitated communication with senior clinicians and managers, before patient harm occurred.

- One of the authors of this paper (SP) was heavily involved in HEADS-UP implementation at two institutions, and in facilitating the use of the data arising from it-a form of participatory research. ${ }^{93}$ His observations, discussions with staff, reflections on clinical governance proceedings and implementation challenges were recorded in field notes over a 20-month period.

- These 'autoethnographic' insights, from researchers embedded within their host organisations, are widely used in organisational case study research, providing rich accounts of culture and practices. ${ }^{51} 9495$

- Observations from the HEADS-UP study informed the narrative synthesis of the literature described here, and the construction of the model of alignment for successful quality improvement interventions.

used to retrospectively describe the implementation of an interdisciplinary intervention (see box 2). The model for alignment emphasises that QI efforts must explicitly meet aligned clinical, managerial and organisational needs if they are to become business as usual'.

\section{ENGAGEMENT-A RECIPROCAL COMMITMENT FROM STAFF AND THEIR ORGANISATION}

There is no universal definition of engagement: it may be an attitude, behaviour, an outcome-or all three. ${ }^{26}$ Schaufeli et $a l^{27}$ describe engagement as an employee's positive motivational state, characterised by 'vigour, dedication and absorption'. A broader, more cooperative, position is that engagement is a two-way phenomenon, with an onus on the organisation to establish conditions encouraging engagement and the opportunities for it to be manifest. ${ }^{28}$ Clinical engagement, then, involves staff actively contributing 'within their normal working roles to maintaining and enhancing the performance of the organisation, which itself recognises this commitment in supporting and encouraging high quality care'. ${ }^{28}$ This working definition makes it clear that real engagement is a very different entity to staff acquiescence, for which it is often confused. ${ }^{29} 30$

In QI, however, clinical engagement has been summarised simply as staff's 'active involvement', ${ }^{31}$ with no recognition of the possible dialogue between clinicians and those seeking to improve their performance. That no organisational contribution is expected may go some way to explaining why clinical engagement has been problematic. Although there is specific literature pertaining to physician engagement, in this discussion (unless specified otherwise) we group clinical healthcare professionals together. QI interventions are typically interdisciplinary, and securing greater engagement of a single staff group is not an end in itself, only a step towards an 'organisational culture where all staff feel valued and involved'.

\section{CLINICAL ENGAGEMENT CAN BE IMPROVED BY CO-DESIGN, LOCAL MODIFICATION AND STRATEGIC SELECTION OF QI INTERVENTIONS}

Healthcare professionals have been reluctant to involve themselves in QI initiatives. ${ }^{31}$ This is especially apparent in periods of sustained organisational turbulence, but is a long-standing, multifactorial and international problem. ${ }^{31}$ Doctors are disproportionately hesitant to participate in safety behaviours like incident reporting, ${ }^{32} 33$ and active resistance from senior staff remains the most common barrier to the successful implementation of interdisciplinary safety checklists. ${ }^{34-38}$ The narrative of 'automatic' clinical resistance to new initiatives, or 'change fatigue', ${ }^{31}$ is seemingly widely accepted within the QI literature. Circumventing this fatigue is considered a major triumph, even fundamental to QI success. With few exceptions, ${ }^{24} 25$ local QI breakthroughs are attributed to good clinical engagement; conversely, failures are seen only through the prism of inadequate clinical buy-in.

Not all interventions are subject to the same clinical disengagement barrier, however: some programmes might have lower thresholds for participation. 213940 Conversely, problems with the introduction of a specific improvement strategy do not necessarily indicate a wider reluctance to change practice. The intervention's characteristics, at least in part, determine its reception. In our experience, iterative co-design of a structured quality and safety briefing intervention with physicians, to maximise its face validity, mitigated much of their expected resistance (see box 2). The process of co-design may also in itself improve staff ownership of the intervention. Other strategies may also have immediate appeal: interventions that used peer facilitation, ${ }^{41}$ wider reporting options and 
Box 2 Applying the model of alignment to analyse Hospital Event Analysis Describing Significant Unanticipated Problems (HEADS-UP) implementation at one study site

- Poor engagement with incident reporting was an organisational concern. However, there was little capacity to enact an improvement programme. No other goals were set aside to prioritise the HEADS-UP programme. As an experimental intervention, the efficacy of HEADS-UP and its implementation strategy was unknown. (Strategic selection of quality improvement (QI) target and intervention)

- Front-line staff expressed initiative fatigue at the beginning of the study, but the face validity of the HEADS-UP tool (and its co-design) mitigated much of their expected resistance, and HEADS-UP was incorporated into normal workflow. QI participation was not formally rewarded, but some junior clinical staff were able to exploit their involvement in HEADS-UP to help with career progression. Others reflected that they found HEADS-UP useful for their own practice and that it improved the quality of interdisciplinary care for their patients, which may have been perceived as a benefit or reward. (Incentives and actions for front-line clinical staff)

- Middle managers were not personally incentivised to participate in HEADS-UP, although an endorsement by the Care Quality Commission during the study period prompted senior managers to designate a greater focus on the programme. Where HEADS-UP generated information to bolster middle managers' existing business plans and develop new ones, those managers coordinated staff-identified opportunities for service development with linked organisational priorities. They gave HEADS-UP their personal backing, encouraging its use, although no additional resources were available to accompany this support. In contrast, middle managers for whom HEADS-UP was less directly useful did less to hold their service areas accountable for HEADS-UP performance. HEADS-UP piggybacked onto existing staff meetings and governance structures: no protected time was made available for involvement in dedicated training, analysis or feedback. Middle managers' time and attention was strictly limited, and competing priorities (eg, the implementation of an electronic health record, or a forthcoming merger) often precluded meaningful progress with this QI intervention. Interestingly, resolution of the persistent issues raised in the HEADS-UP briefings appeared to depend less on each one's inherent safety threat, than on agreement between clinical staff and managers of the need for change. (Incentives and actions for middle managers)

- The organisation focused heavily on clinical quality, investing in external consultants to help develop new clinical services and improve the efficiency of existing ones. Board members also dedicated substantial time to clinical quality issues. In fact, clinical quality was the focus of numerous committees and subcommittees, with a complex, devolved governance structure. However, the regulatory environment did not allow for a self-determined quality strategy, with quality priorities established largely by the local healthcare commissioning body and a national quality inspectorate. Board-level meetings were awash with clinical quality metrics, among which the 'softer data' emerging from the HEADS-UP briefings had a less certain place. ${ }^{96}$ As the organisation moved to merge with another institution, fewer resources were available for continuous QI in the interim. (Incentives and actions for senior managers)

feedback, ${ }^{42-47}$ or engaging whole teams to identify problems ${ }^{48-50}$ all seemingly fell on fertile ground.

Even when QI strategies do not appeal intuitively to clinicians, generating clinical engagement need not prove an insurmountable challenge. Defining the 'soft periphery' of a QI programme-the elements that should be flexibly adapted to optimise the programme's acceptance, without invalidating the entire intervention-is key. ${ }^{51}$ Making the effort to appropriately modify QI tools for the context in which they will be applied (eg, creating separate versions of surgical safety checklists for different specialties) then makes those tools much more palatable for clinicians. ${ }^{34}$ In fact, local adaptation is the most commonly cited factor affecting checklist implementation, more so even than resistance from specific clinicians. ${ }^{34}$ This reflects each organisation's responsibility to create the opportunities for meaningful engagement: active clinical involvement is more likely when QI tools have been purposefully tailored, and when there is protected time for training to use them. ${ }^{31}{ }^{34}$ In contrast, unmodified checklists are unlikely to be used as intended, nor improve patient outcomes-regardless of hospitals' reported compliance. ${ }^{1352}$

While co-design and local modification do improve the adoption of QI interventions, the financial and opportunity costs of pre-existing efforts represent a major challenge to any new initiative. Relentless organisational change, with little sense of an overall strategic direction, also contributes to a general ennui. ${ }^{31}$ Clinicians, believing that each 'fad' will soon be replaced with another, feel there is 'little point in investing heavily in any one initiative'. ${ }^{31}$ The strategic selection of a limited number of QI interventions, appropriate to the organisation's capacity to implement them, is therefore crucial. ${ }^{23} 53$ Experts have identified 22 patient safety strategies with a sufficient evidence base to recommend their widespread adoption: ${ }^{54} 55$ organisations may choose to focus on these first, with a view to their specific local needs. However, if organisations are to select only the QI targets that they have the capacity and willpower to 
pursue, other potentially valuable initiatives need be deferred in the interests of preserving engagement and momentum. Regulatory bodies have an important role here: they should give institutions the time and space to develop these focused improvement strategies. ${ }^{56} \mathrm{It}$ may seem odd to decry the slow pace of improvement, and yet advocate a more deliberate, institutionspecific approach. With space for self-determination, however, organisations that strategically shape their QI attempts go on to see wider benefits, tackling deep cultural issues that go unaddressed with more haphazard approaches. ${ }^{56}$

\section{BEYOND CLINICAL ENGAGEMENT: THE ROLE OF MANAGERS IN QI}

Improving clinical engagement is only part of the solution to ineffective QI: 'administrative engagement is equally important, or disillusionment... ensues'. ${ }^{29}$ Quality of care is not a leading priority for many hospital boards, however. ${ }^{57-59}$ Although board-level attention to quality issues has been associated with clinical quality, ${ }^{575860}$ how this commitment translates, in practice, into front-line action remains unclear. $^{61}$ A recent survey study provided a key insight: board and middle management practices are linked, and correlate strongly with hospital performance on clinical quality metrics. ${ }^{62}$ Certain board characteristics were specifically linked to middle management styles: board attention to quality was associated with management practices that monitored it, and the use of quality metrics at board level corresponded to good operational management and target setting. ${ }^{62}$ If good management is truly associated with clinical quality, the role of managers in QI deserves further attention.

Yet managerial participation in QI interventions is often assumed, rather than analysed in detail. Although senior hospital executives may participate constructively in collaborative safety programmes, ${ }^{14} 63$ more often, active managerial involvement goes no further than the 'expressions of support' described in many QI reports. More detailed evaluations describe difficulties recruiting executives to work with QI teams, even as part of major safety initiatives. ${ }^{25}$ When they do engage, managers have a different outlook on quality and safety programmes to clinical staff, perceiving different components of the programme to be valuable and holding more positive views of the overall results. ${ }^{64}$ Meaningful input from managers is important for the design, monitoring and evaluation of QI interventions; ${ }^{64}$ simply obtaining their permission to proceed is not enough.

There is little published work on the role of managers in QI, the majority of which relates only to senior (board-level) managers, rather than the middle managers under their supervision. ${ }^{59}{ }^{61}$ Importantly, most improvement initiatives fail to specify how they engage these middle managers, with whom front-line staff interact directly and regularly. Middle managers are a particularly heterogeneous group, with diverse professional backgrounds, ${ }^{61}$ often promoted on the basis of a technical skill set rather than any specific leadership or management ability. ${ }^{65}$ Many have 'hybrid' clinical and administrative duties, ${ }^{61}{ }^{66}$ with an inherent tension between those roles; ${ }^{67}$ their decisions are necessarily 'constrained, contested and political, ${ }^{68}$ but favour knowledge drawn from experience rather than research findings. ${ }^{69}{ }^{70}$ Little more is known about the cognitive biases that affect middle managers' judgements, but enthusiasm for QI is not automatic. For example, they may feel the operating costs of QI programmes are not justified by any potential future benefits. ${ }^{71}$ There remains a pressing need for research into how healthcare managers balance their multiple fiscal, statutory and service responsibilities. $^{59}$

\section{INFLUENCING MIDDLE MANAGERS TO FACILITATE EFFECTIVE QI: STATUS, INCENTIVES AND RESOURCES}

It appears, then, that managers contribute to organisational quality; that their active involvement in QI has been taken for granted rather than proven; and that their decision making relating to QI is likely to be complex, with conflicting priorities that are not easily resolved. Yet middle managers, in particular, are uniquely placed to facilitate effective QI. They have the power to accelerate or impede the implementation of innovations, ${ }^{61}$ mediating organisational messages for front-line staff, but also upwardly influencing their seniors to draw attention to the high-level support needed for specific QI programmes. ${ }^{72}$ Acting as information brokers, translating organisational strategy into actionable tasks, and promoting innovative practice, middle managers can convince clinical staff to prioritise QI implementation among numerous competing demands. ${ }^{61}$

Harnessing middle managers' ability to broker organisational and front-line attention to a QI programme may prove essential to its success: proactive commitment from middle managers does influence effective QI implementation. ${ }^{74}$ Although many advocate a clinician-led, 'bottom-up' approach to improvement, ${ }^{75}$ staff-driven initiatives that do not align well with strategic priorities have only limited impact or longevity. ${ }^{71} 76^{77}$ Clear tensions emerge when QI efforts are delegated entirely to clinicians without support for their direction and goals. ${ }^{71}$ Without more senior support, front-line staff are unable to marshal the resources required to spread change, ${ }^{78}$ and managers have an important role to play in navigating cross-departmental obstacles. ${ }^{59}$ Managers who effectively facilitate QI, without micromanaging it, are well appreciated by front-line staff. ${ }^{78}$ The subsequent pace of change may be slow, but a combination of 
top-down and bottom-up implementation results in a lasting impact. ${ }^{78}$

Senior managers play a role in determining middle managers' commitment to QI. These senior managers should directly emphasise QI as an organisational priority, incentivise QI commitment in performance reviews, and-vitally-make available the necessary resources. $^{72}$ In addition, encouraging middle managers to leverage the human resources and performance reviews at their own disposal also improves their commitment to QI implementation. ${ }^{72}$ Interestingly, a performance-related human resources management framework for clinicians has recently been described and implemented, encountering little of the expected physician resistance. ${ }^{79}$ Transparent negotiation of QI goals at each organisational level may therefore be feasible and necessary for high quality implementation.

\section{A MODEL OF ALIGNMENT FOR SUCCESSFUL QI}

We suggest that neither clinicians nor managers can make meaningful QI progress in isolation: their collaboration is fundamental to sustainably embedding practice innovations. The choice of a QI intervention, and its implementation model, both need coordination between clinical and managerial teams. We have discussed, in the preceding sections, how each group might be motivated to take part in this process. Yet their efforts need to be aligned, if QI is to form a significant part of their workload, and not be overwhelmed by other priorities. ${ }^{62}$ We highlight some examples of QI programmes in which the degree of collaboration between front-line and managerial staff may have contributed to the ultimate outcome (table 1). In trials reporting significant improvements, investigators ensured there was adequate managerial participation-or took on managerial roles themselves -to complement clinical involvement. ${ }^{11}{ }^{12} \quad 15 \quad 80$ Similarly, implementation and spread of a QI intervention in a real-world setting was best accomplished with the co-leadership of top-level administrators and front-line champions. ${ }^{78}$ Where managerial engagement was lacking, interventions did not improve outcomes significantly, or systems defects did not prove amenable to the efforts of clinical teams alone. ${ }^{13} 1781$

With this in mind, we propose a simplified model for successful QI interventions (figure 1). This model emphasises, foremost, that QI interventions aiming to change healthcare providers' practice should aim to meet the aligned needs of staff at multiple levels in the organisation. Failing to coordinate these interests renders interventions susceptible to failure, regardless of enthusiasm and engagement at the other organisational levels. In fact, the degree to which an intervention recognises, makes use of, or conflicts with existing staff priorities is fundamental to its success, and should not be considered in the accompanying implementation strategy only. This pre-emptive

Table 1 Descriptions of managerial collaboration in selected quality improvement (QI) interventions

\begin{tabular}{|c|c|c|c|}
\hline QI intervention & $\begin{array}{l}\text { Implementation phase } \\
\text { (proof of concept/trial/ } \\
\text { scaling up) }\end{array}$ & Managerial collaboration & Outcome \\
\hline \multirow[t]{2}{*}{ Surgical safety checklist } & Trial $^{11} 1280$ & $\begin{array}{l}\text { Systems changes facilitated by the local } \\
\text { investigator-essentially fulfilling a dedicated } \\
\text { managerial role. }{ }^{11} \text { Hospital administration/ } \\
\text { management leaders required to 'support the } \\
\text { intervention'11 } 80\end{array}$ & Reduced in-hospital complications \\
\hline & Scaling up ${ }^{13}$ & $\begin{array}{l}\text { No assessment of managerial involvement in } \\
\text { mandatory checklist implementation. Meaningful } \\
\text { local implementation unlikely to have taken } \\
\text { place }\end{array}$ & $\begin{array}{l}\text { No significant change in patient } \\
\text { outcomes }\end{array}$ \\
\hline \multirow[t]{2}{*}{$\begin{array}{l}\text { Program to reduce central } \\
\text { line infections }\end{array}$} & Trial $^{15}$ & $\begin{array}{l}\text { Program targeted middle managers and senior } \\
\text { hospital leaders as well as front-line staff.24 } \\
\text { Chief executives wrote 'commitment letter' to } \\
\text { the program team. Nurse manager led the } \\
\text { project locally; project team also included a } \\
\text { hospital executive advocate }\end{array}$ & Reduced infection rates \\
\hline & Scaling up ${ }^{17}$ & $\begin{array}{l}\text { Chief executives agreed organisations would } \\
\text { participate, and that a director would join the } \\
\text { local project team. In practice, most units } \\
\text { struggled to involve executives }\end{array}$ & No improvement compared with controls \\
\hline $\begin{array}{l}\text { Program to detect and } \\
\text { mitigate organisational } \\
\text { weaknesses }\end{array}$ & Proof of concept ${ }^{81}$ & $\begin{array}{l}\text { Executive sponsor for each site team. } \\
\text { Managerial staff less often directly involved as } \\
\text { project team members }\end{array}$ & $\begin{array}{l}\text { System defects not tractable to small } \\
\text { clinical teams' QI methodology }\end{array}$ \\
\hline $\begin{array}{l}\text { Program to improve } \\
\text { interprofessional } \\
\text { coordination }\end{array}$ & Scaling up ${ }^{78}$ & $\begin{array}{l}\text { Spectrum of managerial involvement. In } \\
\text { 'bottom-up' hospitals, administrators delegated } \\
\text { and served as resources. In 'top-down' } \\
\text { hospitals, managers primarily drove the change } \\
\text { effort }\end{array}$ & $\begin{array}{l}\text { Co-leadership of top-level administrators } \\
\text { and front-line champions best facilitated } \\
\text { implementation and spread of the } \\
\text { intervention }\end{array}$ \\
\hline
\end{tabular}




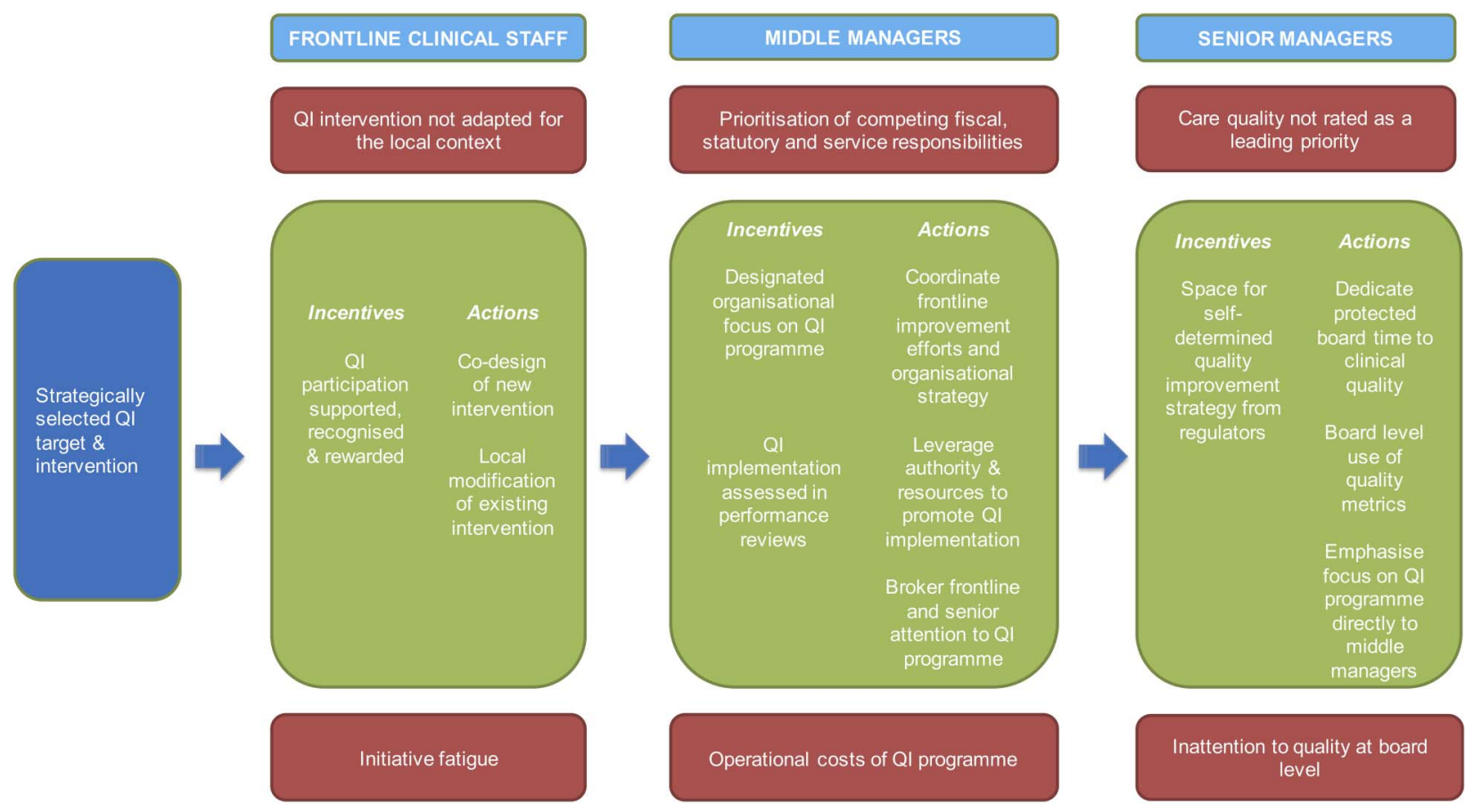

Figure 1 The model of alignment. Strategically selected quality improvement targets and interventions successfully align the interests of clinicians and non-clinicians at multiple levels within the organisation. At each level, staff engagement with these interventions is facilitated by deliberate incentives to prioritise it, the recognition of competing priorities and barriers to involvement, and actions to address them.

consideration of where an intervention is likely to garner support, and the conflicts that need to be resolved to allow wholehearted participation, reflect the 'practical wisdom' thought to be a critical element of successful QI. ${ }^{82}$ Throughout this narrative literature review, and reinforced by our recent practical experience (box 1), we identified specific facilitators that coordinate clinical, middle management and senior management participation in QI. To build a useful model, we then separated these factors into incentives (establishing each group's QI participation as a core expectation of their work) and actions (specific actions by that group that make QI implementation more effective). We also highlight important barriers to aligned QI, again identified from the narrative synthesis. For facilitators and barriers, we focused deliberately on modifiable factors, with a view to building a valid model that has immediate application in practice. Importantly, the inclusion of managers as core members of the QI team may augment what is actually 'modifiable': changes that remain frustratingly out of reach for clinical QI teams ${ }^{81}$ may fall within the remit of an expanded clinical-managerial group.

How could this model be used in practice? Prospectively, clinicians and managers jointly establish and prioritise the challenges facing their service. Multidisciplinary tools systematically collect data relevant to front-line care delivery problems (from staff and patients). ${ }^{83}{ }^{84}$ Teams then assess and rank the apparent safety threats, for example with streamlined versions of tools like Healthcare Failure Modes and Effects Analysis or Hierarchical Task Analysis. ${ }^{81} 85$ These tools inform the strategic selection of high priority targets for local improvement efforts.

Interventions are co-designed or adapted with clinicians, with a focus on the quality strategies for which effectiveness and implementation evidence is strongest. Clinicians' participation is supported, recognised and rewarded, perhaps as part of a formal performance management process. Middle managers coordinate alignment of the improvement efforts with organisational goals, and are themselves heavily incentivised to see QI facilitation as a core role of their own. Influencing their supervisors to attract organisational support and resources for QI efforts, middle managers' interest in quality is further reinforced by protected board time for quality issues, and board-level use of quality metrics. Board members may need to robustly engage with other stakeholders in the local healthcare economy to generate (and protect) an institution-specific quality strategy.

The model can also be used retrospectively, to describe how interventions were implemented in practice, and to explain their effects. We use the model to explore a recent interdisciplinary intervention in our own institutions, describing mutable influences on staff over the course of a trial (see box 2). Definitive progress on a number of key issues occurred only when front-line staff and middle managers agreed the need for change. 
We feel the proposed model of alignment is a useful, novel concept for a number of reasons. First, it emphasises the need to go beyond clinical engagement. Second, it highlights the role of non-clinical staff in sustaining effective QI. Most importantly, it integrates separate literature streams on clinical and managerial influences on QI, lending itself to the prospective design of interventions as well as the retrospective analysis of why they achieved their goals or not. Interestingly, multilevel interventions (explicitly addressing patient, professional and organisational factors, for example) show the most consistent improvements in process and clinical outcomes. ${ }^{86}$ The model of alignment suggests how we might incorporate a similarly multifaceted approach into the design of any new QI intervention. Other authors have recently raised concerns about 'colliding' QI interventions, conceived in isolation but effectively competing in a limited marketplace. ${ }^{87}$ Our model encourages a broader analysis of the environment into which any new QI intervention is launched.

We hope this model will prove useful for future interventions, which will need to more explicitly link their assumptions with underlying theory. ${ }^{88}$ However, it does not negate the value of existing models, which remain well placed to structure QI reporting and evaluation. ${ }^{21-23}$ The model of alignment was derived from a narrative review of the literature, drawing on prior systematic reviews, ${ }^{31} 59$ and tested retrospectively against the experience of implementing a single intervention. It requires more empirical validation, particularly in the prospective design of novel interventions. Lastly, though parsimony is necessary for a 'good' theory of context, ${ }^{88}$ the model of alignment may be too simplistic for some analyses.

\section{CONCLUSION}

Critics of implementation research argue that its theories are no more helpful than common sense. ${ }^{89} 90$ Proponents reply that these theories are open to questioning, while common sense-in itself an informal, 'lay' theory-relies on implicit assumptions that are difficult to challenge. ${ }^{20}$ What we have described here, we hope, might satisfy both camps. Sharing the concern that existing theories offer little to practitioners at the sharp end, and informed by our own recent experience of a complex QI intervention, we offer a focal point for the design and evaluation of future attempts to improve healthcare delivery. The extent to which QI aligns the interests of front-line staff and their managers has not previously been explored in this way.

Perhaps, in truth, we have historically expected too much of clinicians in QI, and demanded too little of their managers. Previous assumptions that managers are well prepared to make meaningful contributions to QI interventions have not been substantiated. ${ }^{59}$ The next generation of guidelines for QI reporting will emphasise narrative understanding, ${ }^{91}$ and this should extend to fuller descriptions of whether clinical and managerial priorities coincided (or collided) within the context of the intervention. Although there are few hard barriers to either group's participation in QI, competing demands force clinicians and managers to rationalise their efforts, and in some cases consciously relinquish other priorities. Developing effective and sustainable QI interventions may depend on our ability to align the two groups' divergent interests.

Twitter Follow Samuel Pannick at @sam_pannick

Contributors The first author conceived the paper and drafted the manuscript, and all authors subsequently revised it for important intellectual content.

Funding This paper represents independent research supported by the National Institute for Health Research (NIHR) Imperial Patient Safety Translational Research Centre (grant

RDPSC79560), the West Middlesex University Hospital NHS Trust and Imperial College Healthcare Charity (grant GG14/ 1022). Sevdalis' research was supported by the National Institute for Health Research (NIHR) Collaboration for Leadership in Applied Health Research and Care South London at King's College Hospital NHS Foundation Trust. Sevdalis is a member of King's Improvement Science, which is part of the

NIHR CLAHRC South London and comprises a specialist team of improvement scientists and senior researchers based at King's College London. Its work is funded by King's Health Partners (Guy's and St Thomas' NHS Foundation Trust, King's College Hospital NHS Foundation Trust, King's College London and South London and Maudsley NHS Foundation Trust), Guy's and St Thomas' Charity, the Maudsley Charity and the Health Foundation. The views expressed are those of the authors and not necessarily those of the NHS, the NIHR or the Department of Health.

Competing interests Nick Sevdalis is the director of London Training \& Safety Solutions Ltd, which delivers team assessment and training to hospitals on a consultancy basis.

Provenance and peer review Not commissioned; externally peer reviewed.

Open Access This is an Open Access article distributed in accordance with the terms of the Creative Commons Attribution (CC BY 4.0) license, which permits others to distribute, remix, adapt and build upon this work, for commercial use, provided the original work is properly cited. See: http://creativecommons.org/licenses/by/4.0/

\section{REFERENCES}

1 Hayward RA, Hofer TP. Estimating hospital deaths due to medical errors: preventability is in the eye of the reviewer. JAMA 2001;286:415-20.

2 Briant R, Buchanan J, Lay-Yee R, et al. Representative case series from New Zealand public hospital admissions in 1998III: adverse events and death. N Z Med J 2006;119:U1909.

3 Zegers M, de Bruijne MC, Wagner C, et al. Adverse events and potentially preventable deaths in Dutch hospitals: results of a retrospective patient record review study. Qual Saf Health Care 2009;18:297-302.

4 Hogan H, Healey F, Neale G, et al. Preventable deaths due to problems in care in English acute hospitals: a retrospective case record review study. BMJ Qual Saf 2012;21:737-45.

5 Dunn EJ, Mills PD, Neily J, et al. Medical team training: applying crew resource management in the Veterans Health Administration. Jt Comm J Qual Patient Saf 2007;33:317-25. 
6 Andersen H, Røvik KA, Ingebrigtsen T. Lean thinking in hospitals: is there a cure for the absence of evidence? A systematic review of reviews. BMJ Open 2014;4:e003873.

7 Fung $\mathrm{CH}$, Lim YW, Mattke S, et al. Systematic review: the evidence that publishing patient care performance data improves quality of care. Ann Intern Med 2008;148:111-23.

8 Wachter RM. Patient safety at ten: unmistakable progress, troubling gaps. Health Aff (Millwood) 2010;29:165-73.

9 Woolf SH, Johnson RE. The break-even point: when medical advances are less important than improving the fidelity with which they are delivered. Ann Fam Med 2005;3:545-52.

10 Huang C, Loewen P, Pelletier T, et al. Implementation of proven interventions in general medical inpatients: development and evaluation of a new quality indicator for drug therapy. Qual Saf Health Care 2008;17:269-74.

11 Haynes AB, Weiser TG, Berry WR, et al. A surgical safety checklist to reduce morbidity and mortality in a global population. N Engl J Med 2009;360:491-9.

12 Haugen AS, Søfteland E, Almeland SK, et al. Effect of the World Health Organization checklist on patient outcomes: a stepped wedge cluster randomized controlled trial. Ann Surg 2015;261:821-8.

13 Urbach DR, Govindarajan A, Saskin R, et al. Introduction of surgical safety checklists in Ontario, Canada. N Engl J Med 2014;370:1029-38.

14 Reames BN, Scally CP, Thumma JR, et al. Evaluation of the effectiveness of a surgical checklist in Medicare patients. Med Care 2015;53:87-94.

15 Pronovost P, Needham D, Berenholtz S, et al. An intervention to decrease catheter-related bloodstream infections in the ICU. N Engl J Med 2006;355:2725-32.

16 Marsteller JA, Sexton JB, Hsu YJ, et al. A multicenter, phased, cluster-randomized controlled trial to reduce central line-associated bloodstream infections in intensive care units*. Crit Care Med 2012;40:2933-9.

17 Bion J, Richardson A, Hibbert P, et al. 'Matching Michigan': a 2-year stepped interventional programme to minimise central venous catheter-blood stream infections in intensive care units in England. BMJ Qual Saf 2013;22:110-23.

18 Benning A, Dixon-Woods M, Nwulu U, et al. Multiple component patient safety intervention in English hospitals: controlled evaluation of second phase. BMJ 2011;342:d199.

19 Taitz JM, Lee TH, Sequist TD. A framework for engaging physicians in quality and safety. BMJ Qual Saf 2012;21:722-8.

20 Nilsen P. Making sense of implementation theories, models and frameworks. Implement Sci 2015;10:53.

21 Taylor SL, Dy S, Foy R, et al. What context features might be important determinants of the effectiveness of patient safety practice interventions? BMJ Qual Saf 2011;20:611-17.

22 Kaplan HC, Provost LP, Froehle CM, et al. The Model for Understanding Success in Quality (MUSIQ): building a theory of context in healthcare quality improvement. BMJ Qual Saf 2012;21:13-20.

23 Harvey G, Jas P, Walshe K. Analysing organisational context: case studies on the contribution of absorptive capacity theory to understanding inter-organisational variation in performance improvement. BMJ Qual Saf 2015;24:48-55.

24 Dixon-Woods M, Bosk CL, Aveling EL, et al. Explaining Michigan: developing an ex post theory of a quality improvement program. Milbank Q 2011;89:167-205.

25 Dixon-Woods M, Leslie M, Tarrant C, et al. Explaining Matching Michigan: an ethnographic study of a patient safety program. Implement Sci 2013;8:70.
26 MacLeod D, Clarke N. Engaging for success: enhancing performance through employee engagement. Department for Business, Innovation \& Skills, 2011.

27 Schaufeli W, Salanova M, González-romá V, et al. The measurement of engagement and burnout: a two sample confirmatory factor analytic approach. J Happiness Stud 2002;3:71-92.

28 Spurgeon P, Mazelan PM, Barwell F. Medical engagement: a crucial underpinning to organizational performance. Health Serv Manage Res 2011;24:114-20.

29 Milliken AD. Physician engagement: a necessary but reciprocal process. CMAJ 2014;186:244-5.

30 Clark J. Medical engagement: too important to be left to chance. The King's Fund, 2012.

31 Wilkinson J, Powell A, Davies H. Are clinicians engaged in quality improvement? A review of the literature on healthcare professionals' views on quality improvement initiatives. London: The Health Foundation, 2011.

32 Evans SM, Berry JG, Smith BJ, et al. Attitudes and barriers to incident reporting: a collaborative hospital study. Qual Saf Health Care 2006;15:39-43.

33 Farley DO, Haviland A, Champagne S, et al. Adverseevent-reporting practices by US hospitals: results of a national survey. Qual Saf Health Care 2008;17:416-23.

34 Russ SJ, Sevdalis N, Moorthy K, et al. A qualitative evaluation of the barriers and facilitators toward implementation of the WHO surgical safety checklist across hospitals in England: lessons from the "Surgical Checklist Implementation Project". Ann Surg 2015;261:81-91.

35 Treadwell JR, Lucas S, Tsou AY. Surgical checklists: a systematic review of impacts and implementation. BMJ Qual Saf 2014;23:299-318.

36 Fourcade A, Blache JL, Grenier C, et al. Barriers to staff adoption of a surgical safety checklist. BMJ Qual Saf 2012;21:191-7.

37 Lingard L, Regehr G, Orser B, et al. Evaluation of a preoperative checklist and team briefing among surgeons, nurses, and anesthesiologists to reduce failures in communication. Arch Surg 2008;143:12-17; discussion 18.

38 O'Connor P, Reddin C, O'Sullivan M, et al. Surgical checklists: the human factor. Patient Saf Surg 2013;7:14.

39 Øvretveit J. Understanding the conditions for improvement: research to discover which context influences affect improvement success. BMJ Qual Saf 2011;20(Suppl 1):i18-23.

40 Øvretveit JC, Shekelle PG, Dy SM, et al. How does context affect interventions to improve patient safety? An assessment of evidence from studies of five patient safety practices and proposals for research. BMJ Qual Saf 2011;20:604-10.

41 Weingart SN, Ship AN, Aronson MD. Confidential clinicianreported surveillance of adverse events among medical inpatients. J Gen Intern Med 2000;15:470-7.

42 Evans SM, Smith BJ, Esterman A, et al. Evaluation of an intervention aimed at improving voluntary incident reporting in hospitals. Qual Saf Health Care 2007;16:169-75.

43 Schuerer DJ, Nast PA, Harris CB, et al. A new safety event reporting system improves physician reporting in the surgical intensive care unit. J Am Coll Surg 2006;202:881-7.

44 Provenzano A, Rohan S, Trevejo E, et al. Evaluating inpatient mortality: a new electronic review process that gathers information from front-line providers. BMJ Qual Saf 2015;24:31-7.

45 Dijkema LM, Keus F, Dieperink W, et al. Real-time information on preventable death provided by email from frontline 
intensivists: results in high response rates with useful information. BMJ Qual Saf 2015;24:288.

46 Nabors C, Peterson SJ, Aronow WS, et al. Physician reporting of clinically significant events through a computerized patient sign-out system. J Patient Saf 2011;7:155-61.

47 Nabors C, Peterson SJ, Aronow WS, et al. Mobile physician reporting of clinically significant events-a novel way to improve handoff communication and supervision of resident on call activities. J Patient Saf 2014;10:211-17.

48 Sujan MA, Ingram C, McConkey T, et al. Hassle in the dispensary: pilot study of a proactive risk monitoring tool for organisational learning based on narratives and staff perceptions. BMJ Qual Saf 2011;20:549-56.

49 Lear R, Vincent C, Van Herzeele I, et al. Structured team self-report of intraoperative error can identify obstacles to safe surgery. Jt Comm J Qual Patient Saf 2013;39:480.

50 King ES, Moyer DV, Couturie MJ, et al. Getting doctors to report medical errors: project DISCLOSE. Jt Comm J Qual Patient Saf 2006;32:382-92.

51 McMullen H, Griffiths C, Leber W, et al. Explaining high and low performers in complex intervention trials: a new model based on diffusion of innovations theory. Trials 2015;16:242.

52 Leape LL. The checklist conundrum. N Engl J Med 2014;370:1063-4.

53 Burnett S, Benn J, Pinto A, et al. Organisational readiness: exploring the preconditions for success in organisation-wide patient safety improvement programmes. Qual Saf Health Care 2010;19:313-17.

54 Shekelle PG, Pronovost PJ, Wachter RM, et al. The top patient safety strategies that can be encouraged for adoption now. Ann Intern Med 2013;158(5 Pt 2):365-8.

55 Shekelle PG, Wachter RM, Pronovost PJ, et al. Making Health Care Safer II: An Updated Critical Analysis of the Evidence for Patient Safety Practices. Comparative Effectiveness Review No. 211. (Prepared by the Southern California-RAND Evidencebased Practice Center under Contract No. 290-2007-10062-I.) AHRQ Publication No. 13-E001-EF. Rockville, MD: Agency for Healthcare Research and Quality. 2013.

56 Jones B, Woodhead T. Building the foundations for improvement. How five UK trusts built quality improvement capability at scale within their organisations. London: The Health Foundation, 2015.

57 Jha A, Epstein A. Hospital governance and the quality of care. Health Aff (Millwood) 2010;29:182-7.

58 Jha AK, Epstein AM. A survey of board chairs of English hospitals shows greater attention to quality of care than among their US counterparts. Health Aff (Millwood) 2013;32:677-85

59 Parand A, Dopson S, Renz A, et al. The role of hospital managers in quality and patient safety: a systematic review. BMJ Open 2014;4:e005055.

60 Jiang HJ, Lockee C, Bass K, et al. Board oversight of quality: any differences in process of care and mortality? J Healthc Manag 2009;54:15-30.

61 Birken SA, Lee SY, Weiner BJ. Uncovering middle managers' role in healthcare innovation implementation. Implement Sci 2012;7:28.

62 Tsai TC, Jha AK, Gawande AA, et al. Hospital board and management practices are strongly related to hospital performance on clinical quality metrics. Health Aff (Millwood) 2015;34:1304-11.

63 Parand A, Dopson S, Vincent C. The role of chief executive officers in a quality improvement: a qualitative study. BMJ Open 2013;3.
64 Parand A, Burnett S, Benn J, et al. The disparity of frontline clinical staff and managers' perceptions of a quality and patient safety initiative. J Eval Clin Pract 2011;17:1184-90.

65 Federico F, Bonacum D. Strengthening the core. Middle managers play a vital role in improving safety. Healthc Exec 2010;25:68-70.

66 Buchanan D. Pure plays and hybrids: acute trust management profile and capacity. J Health Serv Res Policy 2013;18:90-7.

67 Doherty C, Gatenby M, Hales C. Role of the ward sister: tensions, pressures and opportunities. Nurs Stand 2010;24:35-40.

68 Walshe K, Rundall TG. Evidence-based management: from theory to practice in health care. Milbank Q 2001;79:429-57, IV-V.

69 Edwards C, Fox R, Gillard S, et al. Explaining health managers' information seeking behaviour and use. Final report. NIHR Service Delivery and Organisation Programme, 2013.

70 Dopson S, Bennett C, Fitzgerald L, et al. Health care managers' access and use of management research. Final report. NIHR Service Delivery and Organisation Programme, 2013.

71 Morgan L, New S, Robertson E, et al. Effectiveness of facilitated introduction of a standard operating procedure into routine processes in the operating theatre: a controlled interrupted time series. BMJ Qual Saf 2015;24:120-7.

72 Birken SA, Lee SY, Weiner BJ, et al. From strategy to action: how top managers' support increases middle managers' commitment to innovation implementation in health care organizations. Health Care Manage Rev 2015;40: 159-68.

73 Floyd SW, Wooldridge B. Middle management's strategic influence and organizational performance. J Manage Stud 1997;34:465-85.

74 Birken SA, Lee SY, Weiner BJ, et al. Improving the effectiveness of health care innovation implementation: middle managers as change agents. Med Care Res Rev 2013;70:29-45.

75 Braithwaite J, Runciman WB, Merry AF. Towards safer, better healthcare: harnessing the natural properties of complex sociotechnical systems. Qual Saf Health Care 2009;18:37-41.

76 Proudlove N, Moxham C, Boaden R. Lessons for Lean in healthcare from using six sigma in the NHS. Public Money Manage 2008;28:27-34.

77 Rycroft-Malone J, Seers K, Chandler J, et al. The role of evidence, context, and facilitation in an implementation trial: implications for the development of the PARIHS framework. Implement Sci 2013;8:28.

78 Stewart GL, Manges KA, Ward MM. Empowering sustained patient safety: the benefits of combining top-down and bottom-up approaches. J Nurs Care Qual 2015;30:240-6.

79 Trebble TM, Paul M, Hockey PM, et al. Clinically led performance management in secondary healthcare: evaluating the attitudes of medical and non-clinical managers. BMJ Qual Saf 2015;24:212-20.

80 Haugen AS, Softeland E, Eide GE, et al. Impact of the World Health Organization's surgical safety checklist on safety culture in the operating theatre: a controlled intervention study. $\mathrm{Br} J$ Anaesth 2013;110:807-15.

81 Dixon-Woods M, Martin G, Tarrant C, et al. Safer clinical systems: evaluation findings. London: The Health Foundation, 2014.

82 Dixon-Woods M. The problem of context in quality improvement. Perspectives on context. London: Health Foundation, 2014. 
83 Pannick S, Beveridge I, Ashrafian H, et al. A stepped wedge, cluster controlled trial of an intervention to improve safety and quality on medical wards: the HEADS-UP study protocol. BMJ Open 2015;5:e007510.

84 Sheard L, O'Hara J, Armitage G, et al. Evaluating the PRASE patient safety intervention-a multi-centre, cluster trial with a qualitative process evaluation: study protocol for a randomised controlled trial. Trials 2014;15:420.

85 McElroy LM, Khorzad R, Nannicelli AP, et al. Failure mode and effects analysis: a comparison of two common risk prioritisation methods. BMJ Qual Saf 2016;25:329-36.

86 Pinnock H, Epiphaniou E, Pearce G, et al. Implementing supported self-management for asthma: a systematic review and suggested hierarchy of evidence of implementation studies. BMC Med 2015;13:127.

87 Pendharkar SR, Woiceshyn J, da Silveira GJ, et al. What happens when healthcare innovations collide? BMJ Qual Saf 2016;25:9-13.

88 Davidoff F, Dixon-Woods M, Leviton L, et al. Demystifying theory and its use in improvement. BMJ Qual Saf 2015;24:228-38.

89 Bhattacharyya O, Reeves S, Garfinkel S, et al. Designing theoretically-informed implementation interventions: fine in theory, but evidence of effectiveness in practice is needed. Implement Sci 2006;1:5.

90 Oxman AD, Fretheim A, Flottorp S. The OFF theory of research utilization. J Clin Epidemiol 2005;58:113-16; discussion 17-20.

91 Davies L, Ogrinc G. New SQUIRE publication guidelines: supporting nuanced reporting and reflection on complex interventions. BMJ Qual Saf 2015;24:184-5.

92 ISRCTN registry. HEADS-UP: a structured team intervention to improve safety and quality on medical wards. 2015. dx.doi. org/10.1186/ISRCTN34806867 (accessed 1 Oct 2015).

93 Marshall M, Pagel C, French C, et al. Moving improvement research closer to practice: the researcher-in-residence model. BMJ Qual Saf 2014;23:801-5.

94 Watson TJ. Ethnography, reality, and truth: the vital need for studies of 'how things work' in organizations and management. J Manage Stud 2011;48:202-17.

95 Shaw SE, Russell J, Parsons W, et al. The view from nowhere? How think tanks work to shape health policy. Crit Policy Stud 2014;9:58-77.

96 Martin GP, McKee L, Dixon-Woods M. Beyond metrics? Utilizing 'soft intelligence' for healthcare quality and safety. Soc Sci Med 2015;142:19-26. 